\title{
Construções discursivas: as biografias plutarquianas de Teseu e Licurgo
}

Maria Aparecida de Oliveira Silva*

Resumo: Plutarco representa o caso de intelectuais gregos inseridos na vida política do Império cuja particularidade está na formação de uma comunidade grega em Roma que se manifesta na escrita e na reprodução de práticas e costumes da Grécia clássica. A escrita de Plutarco retrata a tendência desses autores em idealizar a Grécia de seus antepassados como forma de firmar sua identidade grega e responder às críticas dos romanos aos seus costumes. Sob essa perspectiva, analisamos a construção discursiva de Plutarco sobre a época arcaica grega nas biografias de Teseu e Licurgo.

Palavras-chave: Plutarco. Identidade Grega. Teseu. Licurgo.

Enxergamos nas narrativas históricas, não apenas dos antigos, mas também dos modernos, a construção de modelos culturais pautados em critérios específicos tratados como se fossem absolutos. $\mathrm{O}$ escopo de tais reflexões encontra-se na intenção desses escritores em preservar a continuidade de seus hábitos e costumes, configurando uma fronteira entre eles e os outros. Para tanto, desqualificam a diferença, associando o estrangeiro ou o diferente a um mal social, uma vez que representa um novo modo de vida e consequentemente uma ameaça à tradição local. O estrangeiro recebe a alcunha de "bár-

* Pós-Doutoranda em Estudos Literários - UNESP/FLC-ar. Bolsista da FAPESP. Endereço eletrônico: madsilva@usp.br

Anos 90, Porto Alegre, v. 16, n. 30, p. 45-60, dez. 2009 
baro", um potencial destruidor de um saber conservado pela tradição ao manifestar traços de sua estranha cultura em suas vestimentas, alimentação, religiosidade etc.

Assim, a figura do estrangeiro atua como uma nova fronteira entre o eu e o outro, a qual assume novas cores e formas de acordo com a região. Um exemplo claro dessa diferenciação é apresentado no estudo de Pollini e Funari (2009, p. 46) sobre as cigarras como indicador de fronteira cultural entre os gregos e os bárbaros, concluindo que "a falta de qualquer narrativa literária, que defina fronteiras precisas entre as cidades gregas e os territórios indígenas, comparáveis àquela indicada por Timeu para essas duas colônias, assim como os outros autores que lidam com a geografia da Magna Grécia, implica tratamentos diferentes para realidades diferentes".

A dificuldade de assimilação do novo espelha-se na exclusão e na depreciação da figura do estrangeiro, o que denota certo medo do outro por trás de sua face vitoriosa. Vitória que se fundamenta em narrativas repletas de façanhas e de ações grandiosas de homens virtuosos em um passado glorioso. A nosso ver, na Roma Imperial, esse respeito à ancestralidade exposto pelos autores gregos - leia-se o conhecimento da tradição cultural grega - acentua a força dessa tra-dição, legitimando-a e excluindo aqueles que não comungam dela, o que simbolicamente faz do estrangeiro um ser não somente apar-tado do corpo social, mas quase sem história, sem memória escrita.

Como Plutarco, esse grego dos gregos, via as condições da Grécia em seu tempo? A pergunta lançada por Barrow move as reflexões apresentadas a seguir. Como o autor nos lembra (BARROW, 1965, p. 131), Plutarco escreveu após duzentos e cinquenta anos de dominação romana na Grécia, ${ }^{2}$ o que significa que Plutarco conhecia não apenas a glória de seu passado, mas também os infortúnios do mundo grego. O profundo conhecimento da literatura grega acumulado por Plutarco, aliado ao seu contexto histórico, permite ao leitor de suas obras compreender a importância da escrita para um grupo de intelectuais gregos, os quais se identificam com a cultura grega e de algum modo desenham suas árvores genealógicas sustentadas por raízes gregas. No entanto, essa comunhão cultural não denota uma unidade de pensamento entre eles, mas uma unidade cultural expressa em diferentes gêneros literários e que, por sua pluralidade 
de formas e de conteúdos, também se realiza das mais diversas maneiras, com os mais diversos fins à época romana.

No caso de Plutarco - essa é a questão central de nossa reflexão -, sua produção literária reflete as discussões de seu tempo sobre o papel dos gregos no Império. Dessa forma, em seus escritos, em especial as biografias, Plutarco reconstrói a história grega em paralelo com a romana e expõe a seu leitor como e por que o mundo grego foi absorvido pelo Império, ao mesmo tempo em que revela como os gregos participaram da construção de Roma. Com isso, Plutarco atribui aos gregos um lugar destacado na história romana, dissociando-os dos demais povos do Império, dos bárbaros. Em certos momentos de sua narrativa, temos a enganosa impressão de que romanos e gregos formam um mesmo corpo, mas uma leitura mais acurada nos revela um corpo cuja cabeça é preenchida por um pensamento grego e, aos romanos, destinam-se as demonstrações de vigor físico e de potência militar.

Em Plutarco, as origens do povo grego remetem-se a dois povos: atenienses e espartanos. Segundo o Catálogo de Lâmprias, há uma biografia de Héracles, desconhecida em nosso tempo, que imaginamos ser o ponto de partida para a criação de Esparta, tal como é a de Teseu para Atenas. Diante dessa limitação, pois não se sabe se essa biografia foi escrita de fato, iniciaremos nossa digressão com as biografias de Teseu e de Licurgo. Parafraseando Plutarco, nossa digressão vai até onde os registros existentes nos permitiram ir. Apesar da limitação dos registros, as histórias das cidades de Esparta e de Atenas figuram nas páginas de Plutarco com enorme riqueza de detalhes. É sabido que as fontes gregas, particularmente as do período clássico, têm suas reflexões centradas nessas duas maiores cidades da Grécia. Contudo, Plutarco esforça-se ao inserir informações sobre outras cidades no cenário histórico dos gregos, como Tebas, Corinto e outras.

Há outros aspectos a serem considerados sobre a possibilidade de escrita de uma biografia de Teseu, personagem tão distante do tempo de Plutarco. Os episódios heroicos de Teseu aparecem registrados em diversas épocas e em várias localidades do Mediterrâneo antigo; as representações do herói podem ser vistas em moedas, estátuas, relevos funerários, vasos, templos, pinturas e mosaicos. As re- 
presentações sobre o mito de Teseu raramente trazem inscrições identificadoras, fato que demonstra a popularidade do herói entre os antigos. ${ }^{3} \mathrm{Na}$ Grécia, no último quarto do século VI a.C., assiste-se ao brusco desabrochar da lenda de Teseu, que se enriquece com uma série de episódios sobre suas aventuras, da cidade de Trezena a Atenas. ${ }^{4}$

O herói Teseu de Trezena é apresentado como o fundador de Atenas em sua biografia e comparado a Rômulo. No original grego, percebemos a sutileza plutarquiana na escolha do verbo anthistemi para referir-se à comparação entre Teseu e Rômulo. Em consulta ao dicionário Lidell-Scott, verificamos que o verbo anthístemi foi usado originalmente apenas em situações de guerra, em campo de batalha. Assim é empregado por Homero, Heródoto, Tucídides, Platão, Aristófanes e outros; somente em Plutarco o verbo anthistemi tem a conotação de comparação. A nosso ver, tal manobra linguística de Plutarco é um indicador de que suas comparações têm o escopo de identificar o mais forte, o mais hábil, o mais capaz em suas funções dentre seus pares, assim como ocorre nos confrontos militares. Os paralelos biográficos de Plutarco são passíveis de múltiplos níveis de comparações entre si, no campo histórico, no filosófico e em outros. É evidente que não há casualidade na escolha da comparação de Teseu, o fundador de Atenas, com Rômulo, o pai de Roma, ambos mitos fundadores.

Segundo o relato plutarquiano, Teseu descendia de famílias áticas e peloponésias; seu pai era um autóctone e sua mãe uma pelópida. ${ }^{5} \mathrm{O}$ perfil de Teseu traçado por Plutarco corresponde a uma origem miscigenada. Nas lutas travadas com vários malfeitores durante a viagem de Trezena a Atenas, é descrito por Plutarco um herói astuto e habilidoso com diferentes armas, ${ }^{6}$ o que pode ser visto como demonstrações de seus talentos advindos da ramificação peloponésia/espartana. No entanto, segundo Plutarco, o feito de maior importância e "maravilhamento" (méga kaì thaumastón) foi a unificação dos demos áticos, criando a cidade de Atenas. É nesse episódio que o herói manifesta suas qualidades de ático, a saber, a exclusão da realeza e a adoção da democracia, em sua política citadina, e ainda o uso da palavra para persuadir os líderes das tribos, uma vez que Teseu visitou e conversou com todos eles. ${ }^{7}$

Assim, na ótica de Plutarco, Teseu surge como uma síntese do povo grego, um ser híbrido, herdeiro de culturas complementares: 
de um lado, a capacidade guerreira dos peloponésios/espartanos e, de outro, a eloquência dos áticos/atenienses. As dessemelhanças entre espartanos e atenienses no campo político parecem grandes, se pensarmos somente nas formas - atenienses são democráticos e espartanos, monarquistas -, mas, se considerarmos a participação dos cidadãos em seu sistema, mostram-se análogos: tanto espartanos como atenienses instituíram leis que concediam espaço para a atuação de seus cidadãos na política citadina.

Heróis como Teseu e Héracles revelam a existência de uma sociedade pautada na violência, sem leis nem letras, que necessita de um ser extraordinariamente forte para conter as inúmeras demonstrações de terror em suas regiões. Nesse sentido, Teseu também atua como um herói civilizador: institui os jogos Ístmicos, elimina os bandidos ao longo do caminho de sua cidade natal até Atenas, combate as Amazonas e põe fim ao tributo instituído por Minos, destruindo o Minotauro. Façanhas que desvelam instabilidades e injustiças imperantes na história arcaica grega, tal como nos retrata Tucídides em sua Arqueologia:

É óbvio que a região agora chamada Hélade não era povoada estavelmente desde a mais alta antiguidade; migrações haviam sido frequentes nos primeiros tempos, cada povo deixando facilmente suas terras sempre que forçado por ataques de qualquer tribo mais numerosa. Não havia, com efeito, movimento comercial e os povos não se aproximavam uns dos outros sem medo, seja por terra, seja por mar, cada povo arava sua própria terra apenas o bastante para obter delas meios de sobrevivência (TUCÍDIDES, 1982, II, 7).

Dentro desse contexto histórico, Teseu assume um caráter de “divisor de águas" na história política da Grécia ao unir as tribos áticas, instituir uma nova forma de governo e garantir a segurança de seu povo com a eliminação de figuras ameaçadoras. Entrevemos no relato plutarquiano que o surgimento da cidade de Atenas representou um momento de pacificação da Grécia, em que o comércio entre o Peloponeso e a Ática tornava-se possível dada a supressão dos perigos que rondavam os caminhos que as $\operatorname{ligavam}^{8} \mathrm{e}$ ainda $\mathrm{O}$ 
equilíbrio político. As alterações nas práticas e nos costumes dos áticos fomentadas por Teseu rompem com o quadro de clausura descrito por Tucídides, já que a partir de seu governo muitos obstáculos à integração desses povos foram eliminados.

É provável que, na biografia de Héracles, Plutarco tenha destinado ao herói peloponésio o mesmo papel civilizador. Considerando-se que a biografia nem tenha sido escrita por Plutarco, podemos inferir, das referências que faz a Héracles na biografia de Teseu, que há correspondência nas ações dos heróis, pois Teseu admirava os feitos de Héracles e procurava imitá-lo. 'Sem a biografia de Héracles para outras reflexões, nossa análise parte de Licurgo, o legislador que inicia uma nova tradição em Esparta, assim como fizera Teseu em Atenas. Em Plutarco, o período arcaico de Esparta também remete à desordem social, então percebemos que o autor beócio traça paralelos entre as histórias dessas cidades e narra como elas encontraram soluções distintas para problemas similares. Com isso, Plutarco nos ensina que as ações devem ser contextualizadas, cada uma delas tem sentidos diferentes, pois está subordinada a seu meio.

Vemos, sob a ótica plutarquiana, que as qualidades de Licurgo espelham-se na retidão de suas ações, na busca de erudição legislativa ao visitar outras cidades e no estabelecimento de leis instauradoras da ordem em Esparta. A origem de Licurgo é restrita ao âmbito da região do Peloponeso; conforme Plutarco, na linha genealógica de Licurgo, ele era o décimo primeiro descendente de Héracles. ${ }^{10}$ Da narrativa plutarquiana, depreendemos que, ao contrário de Teseu e de Sólon, Licurgo não cria condições para o desenvolvimento do comércio em Esparta nem estabelece a democracia como forma de governo. O grande mérito de Licurgo foi ter transformado as leis em preceitos pedagógicos, o que permitiu a assimilação dos ensinamentos destas desde a infância dos espartanos, e também ter afastado seus cidadãos das práticas comerciais.

Diferentemente da realeza da época de Homero, a monarquia espartana possibilita um outro nível de democracia aos cidadãos: no plano das propriedades fundiárias e da distribuição dos cargos políticos. Convém lembrar ainda a educação pública (agogê) recebida por todos e as refeições comuns (sýssitias). O laconismo de Licurgo também contrasta com a eloquência de Teseu; o legislador espartano 
é o de discurso breve (brachylógos) ${ }^{11}$ como Plutarco o caracteriza. Com esses elementos, Plutarco distingue o espartano do ateniense quanto ao sistema de governo, o sistema educacional, a legislação e os hábitos retóricos.

Porém, como gregos, os espartanos exibem seu gosto pela música e pela poesia. Contudo, o gosto espartano explica-se pelo interesse em aperfeiçoar a linguagem, ${ }^{12}$ e não pela simples diversão e consumo de bebidas e alimentos em excesso, como fazem os atenienses em seus banquetes. Concluímos que, a despeito das divergências entre espartanos e atenienses, suas práticas culturais trazem alguns traços característicos ao pensamento grego, embora com finalidades distintas, como a elaboração de leis, a participação dos cidadãos na política citadina, o culto aos deuses olímpicos, as práticas esportivas e outros mais. É provável que o momento político espartano de obtenção da boa ordem (eunomia) ${ }^{13}$ encontre seu equivalente ateniense na biografia de Sólon, já que Teseu não instituiu leis; conforme apontamos anteriormente, é muito provável que seu paralelo na história de Esparta seja Héracles. A ideia de Licurgo como legislador e introdutor da eunomia, boa ordem, em Esparta, já é encontrada em Heródoto:

Licurgos trouxe de Creta essas modificações quando se tornou tutor de Leobotes, seu sobrinho, rei de Esparta. Imediatamente após passar a desempenhar essa função ele mudou todas as instituições e teve o cuidado de evitar qualquer transgressão às mesmas [...]. Assim eles mudaram para melhor as suas instituições, e quando Licurgos morreu os lacedemônios ergueram em sua honra, e até hoje o reverenciam extraordinariamente. E assim, como suas terras eram boas e seus homens não eram poucos, eles logo começaram a prosperar e progredir (HERÓDOTO, 1988, I, 65-66).

De acordo com suas pesquisas, Plutarco apurou que Sólon descendia de atenienses ${ }^{14}$ e, como Licurgo, sua origem acenava para os primeiros habitantes de sua região; assim, ambos eram autóctones. No transcorrer de seu relato, Plutarco nos mostra que muitos dos êxitos desses legisladores se devem a essa ligação de ancestralidade 
com a cidade, o que parece lhes conferir o conhecimento de hábitos e de costumes de seus povos, capacitando-os, com isso, a instituir leis precisas em seus sistemas políticos. A instituição de leis em situação de crise (stásis) desponta assim como um modo natural de agir dos gregos. Apesar de suas diferenças, atenienses e espartanos parecem em consonância com o habitus de seu povo, com o modo político/políade de ser grego, cumprindo e executando leis.

A disciplina espartana de treinamentos militares à época de Licurgo opõe-se às práticas comerciais dos atenienses sob o arcontado de Sólon. Plutarco discorre sobre os motivos que levaram o ateniense a ser comerciante ainda jovem, revelando que os hábitos licenciosos do arconte foram adquiridos em suas viagens comerciais ao estrangeiro. ${ }^{15}$ E será no capítulo vinte e três da biografia de Sólon que as influências sofridas pelo ateniense com a prática do comércio começam a encontrar visibilidade em suas ações políticas. Plutarco critica o legislador por elaborar uma lei que imputava pesadas multas pecuniárias aos condenados no tribunal ateniense. No entender de Plutarco, a cidade de Atenas não possuía moedas suficientes para o acúmulo de grandes quantias, o que evidencia um grande número de condenados ou um exagero de Plutarco. A crítica plutarquiana à lei de Sólon é incisiva: nosso autor vê incongruência em estabelecer multas pagáveis somente com moeda em uma sociedade que raramente a utiliza. ${ }^{16}$

Contudo, o estudo de Barros sobre os poemas de Sólon não menciona qualquer fato relacionado com o tirano ateniense que pudesse comprovar a instituição do pagamento de dívidas judiciárias em moeda corrente. Na visão de Plutarco, com essa lei, Sólon estimulou a procura pelo dinheiro, bem como sua acumulação. No entanto, as palavras de Plutarco não encontram correspondência no discurso de Sólon; o que vemos em seu poema elegíaco, embora incompleto, chamado Eunomia, é a crítica à ambição de seus concidadãos por acumular riquezas, como podemos ver em seu fragmento IV:

Eu sei - e no fundo do meu peito jaz o sofrimento vendo a mais velha terra da Jônia em declínio... 
amor ao dinheiro e o orgulho

E vós, acalmai no peito esse forte coração, vós que, de muitos bens, chegastes ao excesso, moderai a ambição; nem nós cederemos, nem tudo será conveniente para nós

Muitos são maus ricos, e bons, pobres;

Mas nós com eles não trocaremos

O valor pela riqueza; o primeiro é sempre sólido, Mas a riqueza, dos homens ora um ora a outro a possui

(SÓLON, fragmento IV) ${ }^{17}$

Esses versos nos mostram um homem ciente da instabilidade financeira de seu tempo, na qual a riqueza não estava mais concentrada nas mãos de famílias reais, mas circulando entre seus cidadãos, trocando de proprietários conforme o contexto políticoeconômico citadino. Por outro lado, a circulação da riqueza e a instabilidade do momento provocam cisões entre os cidadãos, aguerridos em seus negócios e temerosos em perder suas propriedades. Por tais causas, Sólon prossegue suas exortações no fragmento V:

Ao povo dei tantos privilégios quanto lhes bastam, à sua honra nada tirei nem acrescentei;

mas os que tinham poder e eram admirados pelas riquezas, também neles pensei, que nada tivessem de infamante; de pé, antepondo sólido escudo entre uma e outra facção, a nenhuma delas permiti vencer injustamente

Assim o povo poderia seguir melhor os seus chefes, Nem livre em excesso nem oprimido;

A fartura gera o orgulho, quando muita prosperidade segue Os homens que não têm espírito sadio.

Em assuntos importantes é difícil agradar a todos. (SÓLON, fragmento V) ${ }^{18}$ 
Ainda no capítulo vinte e três, Plutarco relata que Sólon estipulara prêmios em moedas para os vencedores dos jogos olímpicos e ístmicos. Assim, no pensamento plutarquiano, as falhas na elaboração das leis, bem como as indecisões e as inconstâncias políticas de Sólon, representariam erros típicos de um comerciante ou de um homem cuja prática do comércio não lhe foi desconhecida. Na biografia de Licurgo, ao enumerar os percalços de uma sociedade sustentada pela acumulação de metais na forma de moeda, Plutarco justifica suas reprovações ao uso da moeda com valor intrínseco e concorda com a lei licúrgica responsável pela abolição do uso de moedas em Esparta. Em um artigo sobre a cunhagem de moeda na Grécia, Kraay conclui que há, na região do Peloponeso, vestígios materiais que evidenciam a presença de moedas na Arcádia, produzidas no $\mathrm{V}$ a.C. No entanto, na região controlada por Esparta, quase não foram encontrados locais para a produção de moedas antes do séc. V a.C. Contudo, depois da batalha de Leuctras em 371 a.C., os achados arqueológicos comprovam a entrada de moedas na região e ainda locais de cunhagem. ${ }^{19}$

Para Plutarco, a grande vantagem do sistema monetário espartano estava no fato de a moeda não ser cunhada em ouro ou prata, mas ter a forma de feixes grandes e pesados, esculpidos em ferro. Essa moeda, segundo as reflexões plutarquianas, expulsou da Lacedemônia inúmeras injustiças. ${ }^{20} \mathrm{~A}$ nosso ver, Plutarco refere-se à região da Lacedemônia nessa afirmação por considerar Esparta a maior cidade lacedemônica, portanto, capaz de influenciar as demais, tal como sucedia com Atenas na região da Ática. Dessa maneira, não havia um intenso comércio na Lacedemônia por falta da necessária circulação de moedas com valor intrínseco.

Outra ação decisiva para o banimento da moeda em Esparta foi a proibição licúrgica de práticas comerciais na cidade; com isso, no parecer de Plutarco, Licurgo evita a concentração de artesãos com suas artes inúteis e supérfluas. Como a moeda espartana não tinha projeção no mercado grego, não havia intercâmbio comercial entre espartanos e demais povos da Grécia. Assim, os espartanos não podiam comprar mercadorias estrangeiras, o que poderia ser percebido na ausência de navios mercantes em seus portos. Nas palavras de Plutarco, o sistema espartano não comporta nem orador, nem adivinho, nem proxeneta, nem ourives, uma vez que as moedas de ouro Anos 90, Porto Alegre, v. 16, n. 30, p. 45-60, dez. 2009 
e prata foram banidas da cidade e, com isso, mantêm-se isolados dos desregramentos comuns aos que acumulam metais. ${ }^{21}$

A reprovação de Plutarco ao comércio e ao uso da moeda pauta-se nas dificuldades enfrentadas por uma sociedade sustentada pela acumulação de metais, por moedas. Plutarco justifica suas críticas ao uso da moeda com valor intrínseco, argumentando que Esparta tornou-se uma cidade mais justa após as leis de Licurgo:

Primeiro retirou de circulação a moeda de ouro e de prata e decidiu utilizar apenas a de ferro. Também a ela atribuiu valor insignificante quanto ao peso e conferiu-lhe dimensões consideráveis, de forma que, se alguém recebia a quantia de dez minas, precisava de uma carroça para transportá-la e de um cômodo desproporcional na casa para guardá-la. Essa moeda, disseminando-se, expulsou da Lacedemônia muitas injustiças (Licurgo, IX, 2).

Ao expressar tais valores, Plutarco reafirma seu elo com a tradição grega, iniciada por Hesíodo e preservada nos escritos de Xenofonte, de ser a agricultura uma atividade que auxilia na formação moral e militar dos cidadãos, o que se pode depreender da seguinte passagem de Xenofonte:

Nem os mais prósperos podem manter-se afastados da agricultura. Cuidar dela, acho, é ao mesmo tempo uma atividade prazerosa, um meio de fazer crescer o patrimônio e exercitar o corpo para que esteja apto para tudo quanto convém a um homem livre [...]. Ainda que ofereça bens muito abundantes, não permite que os tome para si, ser indolentes; ao contrário, habitua os homens a suportar o frio do inverno e o calor do verão. Exercitando os que lavram com as próprias mãos, aumenta-lhes o vigor, e aos que exercem a vigilância da lavoura torna viris, despertando-os bem cedo e forçando-os a caminhar com passo firme [...]. A terra também incita os lavradores a defender seu terreno, já que nutre seus frutos em espaço aberto, à disposição de quem tenha força para apanhá-los [...]. Seria de admirar, penso eu, se um homem pos- 
suísse algo mais agradável que isso ou se encontrasse uma ocupação mais agradável ou mais útil para a vida (XENOFONTE, 1999, V, 1-11). ${ }^{22}$

No segundo capítulo da biografia de Sólon, Plutarco reproduz o pensamento de Hesíodo, no qual o poeta afirma que trabalhar não consistia nenhum demérito, e acrescenta que o comércio à época de Hesíodo era realizado para trocas de experiências entre os comerciantes, sendo o lucro algo secundário. Então, o fundamental em uma transação comercial era o contato com outras culturas, no firmar de novas alianças com os bárbaros, assegurando a paz entre os povos. Plutarco faz referência aos seguintes versos hesiódicos:

Por trabalhos os homens são ricos em rebanhos e recursos e, trabalhando, muito mais caros serão os imortais O trabalho, desonra nenhuma, o ócio desonra é! Se trabalhares para ti, logo te invejará o invejoso Porque prosperas; à riqueza glória e mérito acompanham. (HESÍODO, 1991, vv. 309-316). ${ }^{23}$

Assim, Plutarco reprova as práticas comerciais atenienses, pois, como membro da aristocracia beócia e proprietário de terras, defende o uso da agricultura como fonte de riqueza. Na estreita relação existente entre o direito à cidadania e a posse da terra na história política greco-romana, justifica-se a preferência aristocrática pela agricultura, considerada uma fonte natural de riqueza. Dessa maneira, pelos caminhos em que os frutos da terra transitavam, aristocratas gregos e romanos conduziam também um ideal de riqueza. Esses cidadãos, respeitados por suas sociedades, consideravam a agricultura a mais notável das atividades; assim, ocupavam-se somente com os produtos vindos da natureza. ${ }^{24}$

Entrevemos na biografia de Sólon a censura de Plutarco à escolha ateniense pelo desenvolvimento do comércio em sua cidade, daí as sucessivas descrições de situações em que Sólon exibe atitudes inconvenientes, todas adquiridas em suas experiências comerciais. Outro aspecto interessante levantado por Plutarco nessa Atenas arcaica é a presença de atitudes místicas, sem racionalidade, que 
resultaram em perseguições daqueles que os cidadãos acreditavam macular a cidade, trazendo maldições e tormentos aos seus habitantes. ${ }^{25} \mathrm{~A}$ desordem imperava em todos os setores da sociedade ateniense, quadro que estimula Plutarco a defender a tirania de Sólon como adequada ao momento histórico da cidade, ${ }^{26}$ uma vez que as leis de Sólon auxiliaram na resolução das divergências de interesses dos atenienses. $^{27}$

A estabilidade alcançada no governo de Sólon transformou Atenas em um lugar atrativo para aqueles que buscavam a segurança e a tranquilidade da cidade. Plutarco relata que, em virtude do grande número de estrangeiros, em especial de comerciantes marítimos, aliado à impossibilidade de cultivo da terra devido à aridez de seu solo, Atenas tornou-se incapaz de absorver e de sustentar tamanho número de pessoas, o que induz Sólon a estimular o comércio maríti$\mathrm{mo}^{28}$ e o artesanato na cidade. Todavia, as mudanças implementadas por ele mantiveram por pouco tempo a harmonia social; logo Atenas viu nascer grupos com diferentes interesses, provocando dissidências internas, condições favoráveis à conspiração de Pisístrato, que teve como desfecho principal sua tomada do poder em Atenas, ocupando o cargo de tirano. ${ }^{29}$

Em suma, a história arcaica grega aparece em Plutarco como uma época em que Esparta ${ }^{30}$ e Atenas lutam contra instabilidades e ações violentas, com heróis afeitos a intermináveis cenas de lutas, nas quais demonstram sua força e habilidades. Em um segundo momento, as duas cidades conseguem resolver suas oposições internas com a instituição de leis, as quais criaram condições para alguns progressos em suas instituições políticas, como a ampliação da participação política dos cidadãos nas decisões políticas. Tanto em Esparta como em Atenas, não existem reis onipresentes como os descritos nas obras de Homero e de Hesíodo. Ainda que governada por tiranos, Atenas atinge um nível de democracia superior ao sistema monárquico e, paradoxalmente, Esparta obtém um sistema político participativo, mesmo sendo uma monarquia.

\section{Discoursive Constructions: The Plutarchean's biographies of Theseus and Lycurgus}

Anos 90, Porto Alegre, v. 16, n. 30, p. 45-60, dez. 2009 


\begin{abstract}
Plutarch represents the case of Greek intellectuals inserted in the political life of the Empire which peculiarity is the constitution of a Greek community in Rome that is shown in the writing and in the reproduction of practices and customs of classical Greece. Plutarch's writing shows the tendency of these authors in idealizing Greece of his ancestors like a form of establishing a Greek identity as well as to respond to the Romans' criticism to the Greeks' customs. Under this perspective, we analyse the construction of Plutarch's discourse during the archaic Greek period considering the biographies of Theseus and Lycurgus.
\end{abstract}

Keywords: Plutarch. Greek Identity. Theseus. Lycurgus.

\title{
Notas
}

${ }^{1}$ Airton Pollini e Pedro Paulo Abreu Funari. "A percepção grega da fronteira na Magna Graecia: Literatura e Arqueologia em diálogo". In: Pedro Paulo Abreu Funari e Maria Aparecida de Oliveira Silva (Orgs.) Política e Identidades no mundo antigo. São Paulo, Annablume/Fapesp, 2009, p. 46.

${ }^{2}$ R. H. Barrow. Plutarch and his Times. Bloomington/London, Indiana University Press, 1965, p. 131.

${ }^{3}$ J. Neils. Lexicon Iconographicum Mythologiae Classicae. Zürich, München: Artemis Verlag. THESEUS, VII, 1994, v. 1. p. 949.

${ }^{4}$ Charles Dugas. “L'evolution de la légende de Thésée”. In: Recueil Charles Dugas. Paris, De Boccard, 1960, p. 61.

${ }^{5}$ Vida de Teseu, III, 1.

${ }^{6}$ Ver capítulos VI a XIII da biografia de Teseu.

${ }^{7}$ Vida de Teseu, XXIV, 1-2.

${ }^{8}$ Vida de Teseu, VI, 6-8.

${ }^{9}$ Vida de Teseu, VI, 6-9.

${ }^{10}$ Vida de Teseu, I, 5.

${ }^{11}$ Vida de Licurgo, XIX, 3.

${ }^{12}$ Idem, XXI, 1.

${ }^{13}$ Heródoto. História. Tradução, introdução e notas de Mário da Gama Kury, Brasília, UnB, 1988.

${ }^{14}$ Vida de Sólon, I, 1.

${ }^{15}$ Idem, II, 1-2.

${ }^{16}$ Idem, XXIII, 3-4.

${ }^{17}$ Tradução de Gilda Naécia Maciel de Barros. In: Sólon de Atenas: a cidadania antiga (com texto original dos poemas e a tradução). São Paulo, Humanitas, 1999, p. 143-145.

${ }^{18}$ Idem, p. 147.

${ }^{19}$ Colin M. Kraay. Archaic and Classical Greek Coins. London, Methuen, 1976, p. 95-100. 
${ }^{20}$ Vida de Licurgo, IX, 1.

${ }^{21}$ Idem, IX, 2-4.

${ }^{22}$ Xenofonte. Econômico. Tradução e Introdução de Anna Lia Amaral de Almeida Prado, São Paulo, Martins Fontes, 1999.

${ }^{23}$ Hesíodo. Os trabalhos e os dias. Tradução, Introdução e Comentários de Mary Macedo de Camargo Neves Lafer, São Paulo, Iluminuras, 1991.

${ }^{24}$ Claude Mossé. “O homem e a economia”. In: Jean-Pierre Vernant. O homem grego. Lisboa, Presença,1993, p. 25.

${ }^{25}$ Idem, XII, 4-6.

${ }^{26}$ Idem, XIII, 3-4.

${ }^{27}$ Idem, XV, 1-2.

${ }^{28}$ Como nos lembra Magalhães: "O mar fornecia os caminhos e rotas que alimentavam as atividades artesanais e mercantis da ágora de Atenas; o mar fazia, ainda, com que uma cidade outrora defendida por cavaleiros e hoplitas de origem rurais tivesse agora sua segurança garantida por marinheiros e remadores”. Cf. MAGALHÃES, Luiz Otávio de. A cidade grega e os modos urbanos da política. In: CARVALHO et al.(Orgs.), 2005, p. 58.

${ }^{29}$ Vida de Sólon, XIX-XXI.

${ }^{30}$ Para reflexões mais acuradas sobre o período arcaico espartano, ver: SILVA, Maria Aparecida de Oliveira. Plutarco historiador: análise das biografias espartanas. São Paulo: Edusp, 2006.

\section{Referências Bibliográficas}

BARROS, Gilda Naécia Maciel. Sólon de Atenas: a cidadania antiga (com texto original dos poemas e a tradução). São Paulo: Humanitas, 1999.

BARROW, R. H. Plutarch and his Times. Bloomington/ London: Indiana University Press, 1965.

DUGAS, Charles. L'evolution de la légende de Thésée. In: Recueil Charles Dugas. Paris: De Boccard, 1960, p. 93-107.

KRAAY, Colin M. Archaic and Classical Greek Coins. London: Methuen, 1976.

MAGALHÃES, Luiz Otávio. A cidade grega e os modos urbanos da política. In: CARVALHO, Margarida Maria; LOPES, Maria Aparecida de S.; FRANÇA, Susani Silveira Lemos (Orgs.). As cidades no tempo. São Paulo: Olho d’Água, 2005, p. 37-59.

MOSSÉ, Claude. As instituições gregas. Lisboa: Edições 70, 1985. 
.Due miti politici: Licurgo e Solone. In: SETTIS, Salvatore (Org.). I Greci: storia, cultura, arte e società. Torino: Einaudi, 1996, p. 1325-1335.

.O homem e a economia. In: VERNANT, Jean-Pierre. O homem grego. Lisboa: Presença, 1993, p. 23-45.

NEILS, J. Lexicon Iconographicum Mythologiae Classicae. Zürich/ München: Artemis Verlag, 1994.

POLLINI, Airton. , Pedro Paulo Abreu. A percepção grega da fronteira na Magna Graecia: Literatura e Arqueologia em diálogo. In: FUNARI, Pedro Paulo Abreu; SILVA, Maria Aparecida de Oliveira (Orgs.). Política e Identidades no mundo antigo. São Paulo: Annablume/Fapesp, 2009, p. 39-58.

SILVA, Maria Aparecida de Oliveira. Plutarco historiador: análise das biografias espartanas. São Paulo: Edusp, 2006.

\section{Fontes Documentais}

HERÓDOTO. História. Tradução, introdução e notas Mário da Gama Kury. Brasília: UnB, 1988.

HESÍODO. Os trabalhos e os dias. Tradução, introdução e comentários Mary Macedo de Camargo Neves Lafer. São Paulo: Iluminuras, 1991.

PLUTARCH. Lives. Tradução Bernadotte Perrin. London/ Massachusetts/ Cambridge: William Heinemann e Harvard University Press, 1988.

TUCÍDIDES. História da Guerra do Peloponeso. Tradução, introdução e notas de Mário da Gama Kury. Brasília, UnB, 1982.

XENOFONTE. Econômico. Tradução e introdução Anna Lia Amaral de Almeida Prado. São Paulo: Martins Fontes, 1999. 